\title{
Bir Tekstil İşletmesinde Simülasyon Yardımıyla Süreç lyileştirme
}

\author{
Process Improvement in a Textile Firm Using Simulation
}

\author{
Nuri Özgür DOĞAN ${ }^{1}$, Ebru TAKCI²
}

\begin{abstract}
ÖZET
Bu çalışma Kayseri'de faaliyet gösteren bir tekstil fabrikasında gerçekleştirilmiş ve esas olarak süreç iyileştirme yapılarak işgücü, malzeme ve teçhizat gibi kaynakların istenen kapasite doğrultusunda en etkin bir şekilde kullanııması amaçlanmıştır. Fabrikanın verimli çalışmasına engel olan üretim hattındaki darboğaz noktalar tespit edilmiş ve bunların ortadan kaldırılmasına çalışıımıştır. Bu kapsamda mevcut montaj hattı dengelenmiş, yapılması düşünülen iyileştirmelerin imalat sistemi üzerindeki etkileri ise simülasyon yardımıyla incelenmiştir. Mevcut ve gelecek durum simülasyon modelleri çalıștııımıs ve her iki modelden elde edilen çıktılar karşılaştırımıştır. Gelecek durum için önerilen modelde hiçbir ek kaynak eklemeden mevcut kaynaklar aynen kullanılmıştır. Mevcut durum simülasyon modelinden elde edilen yıllık üretim miktarı ile gelecek durum modelinden elde edilen yıllık üretim miktarları karşılaştıııldığında, gelecek durum için önerilen simülasyon modelinin yıllık \% 47 oranında daha fazla ürün verdiği görülmüștür. Bu artışın ișletme verimliliğini ve gelecekte alınacak olan yönetimsel kararları büyük ölçüde etkileyebileceği öngörülmüştür. Son olarak çalışmanın bazı kısıtları olduğu vurgulanmış ve gelecekte bu konuda araştırma yapacaklara birtakım öneriler sunulmuştur.
\end{abstract}

Anahtar kelimeler: Süreç İileştirme; Tekstil ve Hazır Giyim Sektörü; Simülasyon.

\section{GíRiş}

Tekstil ve hazır giyim sektörü dünyadaki birçok ülke için olduğu gibi Türkiye için de son derece önemli sektörlerdendir. 2011 yılı ihracat verilerine göre dünya genelinde tekstil ticareti 349 milyar dolar; hazır giyim ticareti ise 410 milyar dolar düzeyinde gerçekleşmiştir. 2012 yılında ise bu değerler sırasıyla tekstil için 332 milyar dolar, hazır giyim içinse 409 milyar dolar olmuştur. 2012 yılında dünya ticaretinin yaklaşık olarak \% 5'i bu sektörlerde gerçekleşmiştir. Yine 2012 yılı verilerine göre Türkiye, hem dünya tekstil ihracatında hem de hazır giyim ihracatında \% 3,5'lik paylar ile yedinci büyük ihracatçı konumundadır (Bilim, Sanayi ve Teknoloji Bakanlığı, 2013).

Tekstil ve hazır giyim sektörü, deri sektörü ile birlikte değerlendirildiğinde; Türkiye'nin GSYH'sinin \% 10 'undan fazlasını ve imalat sanayinde yaratılan katma değerin de yaklaşık olarak \% 16'sını sağlamaktadır. Ayrıca 2012 yılı verilerine göre tekstil sektöründe

\begin{abstract}
This study was performed in a textile factory in Kayseri and essentially process improvement was made with the aim of using the resources such as labour, material and equipment in a most efficient way in accordance with the capacity. The bottleneck points in the production line that prevent the productive work of the factory were determined and tried to be eliminated. In this context, the current assembly line was balanced and the effects of the allowable improvements on the manufacturing system were analyzed using simulation. The current and future state simulation models were run and the outputs of the both models were compared. The current resources were also used in the future state simulation model without using any additional resource. When the annual production quantities of the current and future state simulation models were compared, it was seen that the proposed model's outputs were more than the current one's with the ratio of \% 47 . It was foreseen that this rise could effect the productivity of the firm and the probable managerial decisions. Finally, limitations of this study and the research areas are pointed out for future research on this subject.
\end{abstract}

Keywords: Process Improvement; Textile and Apparel Industry; Simulation.

17313, hazır giyim sektöründe ise 33977 işyeri faaliyet göstermekte sırasıyla bu sektörlerden tekstilde 430213, hazır giyimde ise 454754 kişi istihdam edilmektedir (Bilim, Sanayi ve Teknoloji Bakanlığı, 2013).

Ekonomi Bakanlığı (2014) verilerine göre bu sektörlerden özellikle hazır giyim sektörünün ihracattaki payı ile daha önde yer aldığı görülmektedir. Hazır giyim ürünleri ihracatı, 2012 yılında 13,90 milyar dolar, 2013 yılında ise 14,96 milyar dolar olarak gerçekleşmiştir. Türkiye'nin 2012 yılındaki toplam ihracatı 152,46 milyar dolar, 2013 yılındaki toplam ihracatı ise 151,80 milyar dolardır. Bu veriler hazır giyim sektörünün büyüklüğünün anlaşılmasına yardımcı olacak cinstendir.

Son zamanlarda rekabetin giderek artması, özellikle en büyük rakip konumundaki Asya ülkelerinin ucuz işgücü avantajını elinde bulundurması Türkiye'deki tekstil ve hazır giyim işletmelerini tehdit etmektedir. Böyle olunca güçlü rakipler ile rekabet

'Yrd.Doç.Dr., Nevşehir Hacı Bektaş Veli Üniversitesi, İktisadi ve İdari Bilimler Fakültesi, İşletme Bölümü; nodogan@nevsehir.edu.tr

${ }^{2}$ Yalın Üretim Şefi, Kayseri Kilim Mobilya; ebrutakci@gmail.com 
ederken verimlilik ve/veya etkinlik kavramlarına her zamankinden daha fazla önem verilmeli; kaynakların en rasyonel şekilde kullanılmasına dikkat edilmelidir.

Ancak sektörde faaliyet gösteren işletmelerin çoğunda kaynakların etkin kullanılamaması, üretim hatlarında darboğazların ya da dengesiz iş akışlarının oluşması şeklinde temel sorunlar yaşanmaktadır. Bu sorunlar etkinliği / verimliliği düşürmekte; bu da dolaylı olarak kalite ve müşteri memnuniyetini olumsuz etkilemektedir.

Bu çalışmada Kayseri'de faaliyet gösteren hazır giyim imalatçısı ve aynı zamanda ihracatçı olan bir işletme ele alınmış ve bu işletmedeki süreç iyileştirme çalışmasına yer verilmiştir. Çalışmaya konu olan işletme, toplam üretiminin yaklaşık \% 30'unu iç pazara, \% 70'ini de dış pazara arz etmektedir. İşletmede üretim akışında birtakım sorunlar yaşanmakta ve kapasitenin yeterince kullanılamadığı anlaşılmaktadır. Bu temel sorunlar üretim süreçlerinde darboğazların yaşanmasına neden olmakta, kaynaklar etkin kullanılamamakta ve bunların geri planında ise işletmenin mevcut yerleşim planının olduğu görülmektedir. Bu çalışmanın temel amacı hazır giyim sektöründe faaliyet gösteren bu işletmeye mevcut sorunlarının elimine edildiği bir gelecek durum üretim sürecinin önerilmesi ve bu önerilen duruma geçilmesi halinde işletmenin ne türden kazanımlar elde edileceğinin gösterilmesidir. Bu kapsamda önce mevcut durum üretim süreci ortaya çıkarılmış, sorunların giderildiği gelecek durum için önerilen sürecin getirileri ise simülasyon yöntemi ile gösterilmiştir.

Çalışmanın planı şu şekilde oluşturulmuştur: İkinci bölümde süreç iyileştirme ile ilgili gerçekleştirilmiş çalışmalara ilişkin literatür özeti verilmiştir. Üçüncü bölümde denim pantolon üreten bir hazır giyim işletmesinde yapılan süreç iyileştirmeye ilişkin uygulama anlatılmıştır. Çalışma genel bir değerlendirmenin yer aldığı dördüncü bölüm olan sonuç bölümü ile bitmiştir.

\section{LITERATÜR ÖZETi}

Bu bölümde literatürde yer alan süreç iyileştirme çalışmalarına ilişkin literatür özetine yer verilmiştir. Literatürdeki çalışmalara geçmeden önce süreç ve süreç iyileştirme kavramlarına değinmek yararlı olacaktır. Üretim yönetiminde süreç denildiğinde en basit ifadeyle; girdilerin bir üretim sürecinden geçerek çıktıya dönüştüğü operasyonlar dizisi akla gelmektedir. Süreç planlaması ise istenilen ürün ya da hizmetin istenilen miktarda, en uygun zamanda ve kabul edilebilir maliyetle üretilmesini sağlayacak bir üretim sisteminin tasarlanması ve uygulanmasına ilişkin faaliyetleri kapsamaktadır (Monks, 1996: 153). Süreç yönetiminde süreçlerin sürekli ve düzenli olarak izlenmesi ve geliştirilmesini garanti altına almak için çalışmalar yapılmaktadır. Bu kapsamda süreçlerin tasarımı, sürdürülmesi, müşteri beklenti ve ihtiyaçlarının daha iyi karşılanması için sürekli değerlendirme, analiz ve iyi- leştirmeler yapılmaktadır (Bozkurt, 2003: 8).

Literatürdeki çalışmalar incelendiğinde; süreç iyileştirmenin çok çeşitli alan ya da sektörlerde uygulandığını görmek mümkündür. Bunlara; inşaat sektörü (Freire ve Alarcon, 2002), tarımsal gıda sektörü (Schiefer, 2002), elektronik (Chan ve Spedding, 2003), yazılım endüstrisi (Baddoo ve Hall, 2003; Beecham vd., 2005; Niazi vd., 2005; Pino vd., 2008), motor ve traktör imalatı (Kaya ve Ağa, 2004), hizmet sektörü (Tütüncü vd., 2004; Eleren, 2007), otomotiv yan sanayii ( Tezsürücü ve Tunail, 2010), imalat sektörü (Yılmazer ve Sarıaltın, 2011; Kamath vd. 2013) ve sağlık sektörü (Ince vd., 2013) çalışmalarını örnek olarak vermek mümkündür.

Literatürde tekstil sektöründe gerçekleştirilmiş süreç iyileştirme çalışmaları da yer almaktadır. Holmes vd. (1998) kağıttan yapılan giysi üretimine odaklandıkları çalışmalarında bir tekstil işletmesinde kalite iyileştirme konusunu ele almışlar ve bu amaçla işletmenin üretim süreçlerindeki değişkenliği azaltmak için istatistiksel proses kontrol ile otomatik proses kontrol yöntemlerinden yararlanmışlardır.

Forsyth ve Porter (2000) hazır giyim imalatçısı küçük bir işletmede üretim planlama ve kontrol çalışmaları gerçekleştirmişlerdir. Üretim süreçlerinin planlanmasında ve kontrolünde bazı sorunlar yaşayan işletmede yaklaşık iki yıl boyunca iyileştirme çalışmaları yapılmıştır. Başlangıçta \% 24 olan zamanında teslimat oranı gerçekleştirilen iyileştirme projesi sonrasında \% 85 'e yükselmiştir.

Wong ve Chan (2001) giyim imalatçısı bir işletmenin proses planlamasında yapay zeka yönteminden yararlanmışlardır. Genetik algoritmanın kullanıldığı planlama çalışmasında önerilen yeni süreç ile birtakım etkili sonuçlara ulaşılmıştır. Stok ve taşıma maliyetleri büyük ölçüde azaltılmış, indirimli ürünlere ilişkin müşteri şikayetlerinin de önüne geçilmiştir.

Hashemipour (2004) Kuzey Kıbris'ta tekstil sektöründe faaliyet gösteren bir imalat işletmesinde bilgisayar destekli proses planlama ve çizelgeleme çalışması gerçekleştirmiştir. Çalışma kapsamında mevcut üretim sistemi dikkate alınmak koşuluyla yeni bir siparişin gelmesi halinde üretim maliyetleri ile siparişin teslimat tarihine bakılmış ve dış kaynaklardan yararlanma durumu incelenmiştir. Ayrıca önerilen süreç değişikliği ile maliyeti azaltmak ve teslimat tarihini kısaltmak amacıyla ürün tasarımında da bazı değişikliklerin yapılabileceği görülmüştür.

Kwong vd. (2006) tam zamanında üretimin uygulandığı tekstil imalatı için hatalardan etkilenmeyecek şekilde kumaş kesim çizelgelerini belirlemeyi amaçladıkları çalışmalarında yöntem olarak genetik algoritma ile bulanık küme teorisini kullanmışlardır. Önerilen yöntem Çin'de hazır giyim imalatı yapan bir tesiste gerçekleştirilen iki vaka analizi ile gösterilmiş ve sonuçta üretim akışları dengelenmiş, sistemin per- 
formansı daha güvenilir ve tutarlı hale getirilmiş ve üretim maliyetlerinde de azaltma elde edilmiştir.

Laoboonlur vd. (2006) bir örme kumaş boyama ve apre tesisinde üretim planlama çalışması gerçekleştirmişlerdir. Çalışmada sezgisel yöntemlerden yararlanılmış ve araştırmaya konu olan tesise özgü çizelgelemeler test edilmiştir. Eroğlu (2006), bir çorap üretim firmasında süreç iyileştirme üzerine uygulama gerçekleştirmiş ve uygulama sonucunda; kaynakların daha etkin ve verimli kullanılması sağlanmış, ayrıca maliyetler ve müşterilerden gelen şikayetler azaltılmıştır.

Mukhopadhyay ve Ray (2006) Altı Sigma yöntemini kullanarak iplik paketlerinde (yumaklarında) karşılaşılan hataların azaltılması amacıyla bir çalışma gerçekleştirmişlerdir. Çalışma Hindistan'da faaliyet gösteren bir tekstil işletmesinde gerçekleştirilmiş süreçlerde iyileştirmeye gidilerek paket ağırlıklarında yaşanan varyasyonların önüne geçilmiştir.

Tang vd. (2006) bilezikli eğirme prosesini simülasyonla modellemiş ve bu sayede farklı koşullar altında iplik gerginliğini etkileyen parametreleri belirlemişlerdir. Raja ve Suryaprakasa Rao (2007) ise bir pamuk eğirme sisteminin performansını simülasyon yönteminden yararlanarak değerlendirmişlerdir. Geliştirilen simülasyon modeli iplik kırılmalarının olmayacağı ve makinelerin izleyebileceği optimum rotaların belirlenmesi için kullanılmıştır.

Greasley (2008) tekstil imalatçısı uluslararası bir işletmenin depolama alanlarının büyüklüğünün belirlenmesinde simülasyon yönteminden yararlanmıştır. Yöntemin uygulanmasıyla işletme içindeki departmanlararası ilişki ve yerleşim ile süreçteki akışlarda oluşan kuyrukların davranışları da incelenmiştir.

Webb vd. (2010) tekstil sektörü içerisinden spesifik bir alana odaklandıkları çalışmalarında görselleştirme ve simülasyon yöntemlerini kullanarak ipliklerin birleştirilmesi sürecini modellemişlerdir.

Yang vd. (2011) giyim endüstrisi içerisinde moda sektörü üzerine bir çalışma gerçekleştirmişlerdir. Tamsayılı programlama ile karınca koloni optimizasyon yöntemlerinin kullanıldığı çalışmada üretim süresinin kısaltılması ve maliyetlerin minimize edilmesi amaçlanmıştır. Bu amacı gerçekleştirecek üretim süreçlerinin belirlenmesine çalışıımış ve bu kapsamda en ekonomik kesim modellerini veren yerleşimler araştırılmıştır.

Zülch vd. (2011) hazır giyim imalatçısı bir işletmede üretim süreçlerinde meydana gelecek değişmelerin etkilerini simülasyon yöntemiyle incelemişlerdir. Kişiye göre özel üretim yapılması durumunda üretim akışlarında meydana gelecek değişmeler farklı senaryolar kurularak; üretim lojistiği ve finansal boyut bakımından incelenmiş ve elde edilen sonuçlara göre işletmeye birtakım öneriler getirilmiştir.

Chen vd. (2012) hazır giyim sanayiinde üretim hatlarının yeniden tasarlanması problemini ele almışlardır. Çalışmada bölüm olarak dikimhane seçilmiş ve hazır giyim fabrikalarının gerçek verileri kullanılmıştır. Yöntem olarak grup genetik algoritma kullanılmış ve dikim hattındaki ortalama mutlak sapmaların minimize edilmesi amaçlanmıştır. Sonuç olarak; çevrim süresinin kısalması, elde edilen ürün çıktısı ile operatörlerin kullanım oranlarının artması elde edilen iyileştirmeler olmuştur.

Şener ve Kılınç (2013), Konya'da faaliyet gösteren ve aynı ürünü üretmekte olan üç hazır giyim işletmesinde bayan ceket üretiminde uygulanan farklı dikim süreçlerinin analizini yapmışlar ve süreçle ilgili öneriler sunmuşlardır.

Islam vd. (2013) Bangladeş'te hazır giyim sektöründe faaliyet gösteren bir imalat işletmesinde kalite ve verimlilik iyileştirmesi üzerine bir çalışma gerçekleştirmiştir. Üretim süreçlerindeki varyasyonlar tespit edilerek bunlar kontrol altına alınmış; böylece yeniden işlemler önemli ölçüde azaltılmış, kaynaklardan daha iyi yararlanılması sağlanmış ve süreç çıktılarında istenilen kalitenin sürdürülmesi mümkün olmuştur.

Alkaya ve Demirer (2014) dokuma kumaş imalatçısı bir işletmede sürdürülebilir tekstil üretimi üzerine bir çalışma gerçekleştirmişler ve önerilen sürdürülebilir üretime geçilmesi durumunda elde edilecek çevresel ve ekonomik getirileri ortaya koymuşlardır.

Brahmadeep ve Thomassey (2014) bir iplik boyama fabrikasında gerçekleştirdikleri çalışmada iplik sarma ünitesinde üretim akışını ve bobinlerin dağıtım mantığını açıklamayı amaçlamışlardır. Yöntem olarak simülasyonun kullanıldığı çalışmada mevcut durumdaki manuel sistem ile gelecek durum için önerilen otomatik sistem kurulan simülasyon modelleri ile karşılaştırılmıştır.

Literatürde yer alan süreç iyileştirme ile ilgili çaIışmalar incelendiğinde; tekstil ve/veya hazır giyim sektörü üzerine gerçekleştirilmiş çok sayıda çalışmanın olduğu görülmüştür. Ancak özellikle Türkiye'de gerçekleştirilmiş çalışmaların sayısı kısıtlıdır. Bu çalışma, hazır giyim sektörü içerisinde denim pantolon üretimi üzerine yapılmasıyla ve ayrıca simülasyon yönteminin kullanılmasıyla literatürde yer alan diğer çalışmalardan farklılaşmaktadır.

\section{YÖNTEM}

Çalışmada yöntem olarak simülasyondan yararlanılmıştır. Simülasyon, gerçek sistemin davranışının bilgisayar ortamında taklit edilmesidir. Simülasyon ya da diğer adıyla benzetim, çalışan bir sistemi değiştirmeden ya da durdurmadan o sistem üzerinde ne türden değişiklikler yapabileceğimize ilişkin önemli fikirler verir. Ayrıca, gelecek durumda sistem üzerinde yapılabilecek iyileştirmeye dönük değişikliklerin sistem üzerindeki etkilerini önceden görebilmemize olanak sağlar.

Bir simülasyon modeli geliştirilirken sırasıyla birtakım adımların izlenmesi gerekir. Bunlar; sistemin incelenmesi, modelin formülasyonu, model mantığının 
doğrulanması ve geçerliliğinin saptanması, deneylerin planlanması, sonuçların analizi ve yorumlanması şeklindedir (Sarıaslan, 1986: 44-46).

\subsection{Uygulamanın Yapıldığı İşletmeye İlişkin Tanıtıcı Bilgiler}

Çalışmanın uygulaması tekstil sektöründe faaliyet gösteren bir imalat işletmesinde gerçekleştirilmiştir. Kayseri ilinde bulunan işletmede ağırlıklı olarak denim pantolon üretilmekte olup, işletmenin bünyesinde modern teknolojik donanımlara sahip modelhane, kesimhane, dikim üniteleri, yıkama, finish ve paket bölümleri mevcuttur. Toplam kapalı alanı 5000 $\mathrm{m}^{2}$ olan işletme, aylık ortalama 65000 adet dikim ve 120000 adet yıkama kapasitesine sahiptir.

\section{2. İşletmedeki Ürün Akışı}

İşletmedeki denim pantolon sürecine ilişkin ürün akışı Şekil 1'de gösterilmiştir. Modelhanede siparişi alınan modellerin koleksiyonları hazırlanmakta; kalıpları, serilemesi ve pastal planı çıkartılmaktadır. Model ve koleksiyon için gerekli aksesuarlar belirlenip depoya bildirilmektedir. Üretime geçmeden önce örnek dikim yapılmakta, örnek dikim onaylandıktan sonra üretime geçilmektedir. Pastal planı hazırlanan modelin kesimhanede kesim işlemi yapılmakta, kesilen parçalar dikilmek üzere ilgili dikim hattına gönderilmektedir. Dikilmiş olan pantolona yıkama ve yan işlem bölümlerinde efekt kazandırılmakta, finish bölümünde ise ütü, kalite kontrol, metal çakımı gibi operasyonlar yapılmaktadır. Daha sonra finish bölümünde sevkiyata hazır hale gelen ürünler paket bölümüne sevk edilmektedir.

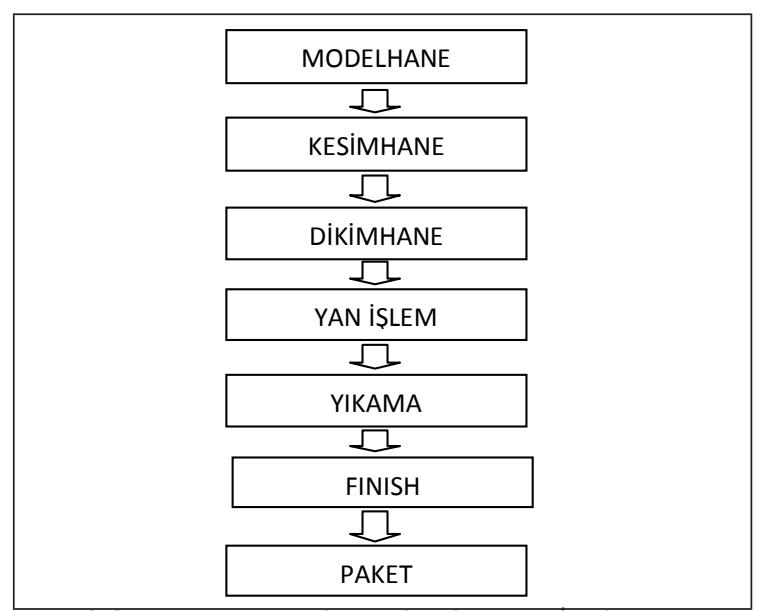

Şekil 1: Denim Pantolon Bölümler Arası Iş Akış Şeması

Şekil 1'den de görüleceği üzere araştırmaya konu olan üretim tesisi yedi ana bölümden oluşmaktadır. Bu ana bölümlerden modelhane, kesimhane ve paketleme üretimden bağımsız olup, çıkan ürünü doğrudan etkilememektedir. Dolayısıyla bu üç bölüm uygulama kapsamına alınmamıştır. Uygulamanın kapsamına üretimi doğrudan etkileyen dikimhane, yan işlem, yıkama ve finish birimleri alınmıştır. Hammadde olarak dikimhaneye gelen parçalar dikilerek yarı mamul hale gelmekte, yan işlem ve yıkama bölümünde yarı mamullere efekt kazandırılmakta, finish bölümünde ise yarı mamul, mamul hale getirilmektedir.

Dikimhane ön, arka ve montaj bölümü olmak üzere üç bölümden oluşmaktadır. Dikilecek olan pantoIonun ön kısmı ve arka kısmı sırasıyla ön ve arka bölümlerde gerçekleşmektedir. Montaj bölümünde ise pantolonun hazırlanmış olan ön ve arka kısımlarının montajı yapılmaktadır. Dikim işlemi biten pantolona yan işlem ve yıkama bölümlerinde efekt kazandırılmakta; yıkama işlemi tamamlanan pantolon finish bölümünde paketlemeye ve sevkiyata hazır hale getirilmektedir. Finish bölümünde operasyonu tamamlanan pantolonlar, sevkiyatı yapılmak üzere paket bölümüne gönderilmektedir. Denim pantolonun dikimden paketlenmeye kadar geçtiği aşamalar Şekil 2'de gösterilmiştir.

\subsection{Mevcut Durumda Üretim Akışında Yaşanan Sorunlar ve Bu Sorunların Çözümüne illişkin Gelecek Durum Önerisi}

Mevcut durumda üretim akışında birtakım sorunların olduğu gözlenmiştir. Tespit edilen başlıca sorunlar aşağıda sıralanmıştır:

- Hat içinde yer alan insan kaynakları ve cihazların etkin kullanılamadığı görülmektedir.

- Etkin kullanılamayan kaynaklar verimsiz işgücüne sebebiyet vermekte, bu durum da nihai ürün sayısını düşürmektedir.

- Darboğaz noktalar tespit edilip, problemlere çözüm üretilemediğinden dolayı hat dengeleme problemleriyle karşılaşılmaktadır.

- Zemin katın geniş olmasına rağmen, sadece dikimhane ve kesimhane bölümlerinin bu katta yer alması zemin katı atıl duruma düşürmektedir. Aynı zamanda yan işlem, yıkama, finish ve paket bölümlerinin dördünün de bodrum katında yer alması iş akışında karışıklıklara yol açmaktadır.

- İş akışındaki ve bölümler arası karışıklıklar zaman kayıplarına sebep olmakta bu durum da ürünlerin zamanında sevkiyatını engellemekte ve dolayısıyla termin sürelerine uyulamamaktadır.

- Termin sürelerine uymak için yapılan fazla mesailer işletme için ek maliyet olmakla beraber, çalışan performansını da olumsuz etkilemektedir.

- Termin sürelerine uymak amaçlı yapılan hızlı çalışmalar, hat içinde kalite problemlerine sebep olmakta bu durum da çalışanlar arasındaki koordinasyonu engellemektedir.

- Termin sürelerindeki gecikmeler ve hızlı çalışmadan doğan kalite problemleri aynı zamanda müşteri memnuniyetini olumsuz etkilemekte, güven kayıplarına yol açmaktadır.

Mevcut durumdaki sözü edilen sorunların çözümüne ilişkin olarak bir takım öneriler geliştirilmiş ve gelecek durumda birtakım düzenlemelerin yapılmasıyla sürecin iyileştirilebileceği düşünülmüştür. 


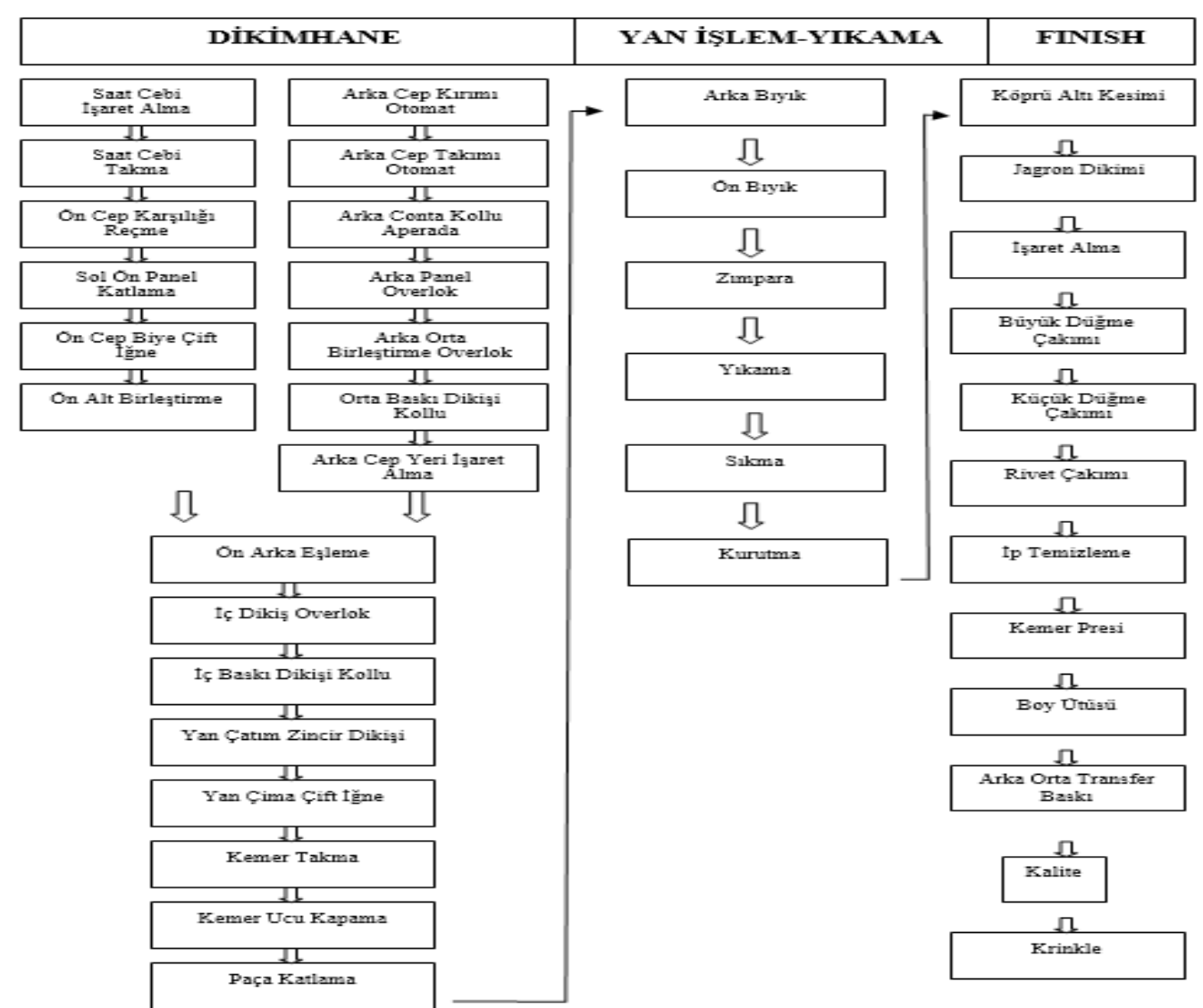

Şekil 2: Denim Pantolon İş Akış Şeması

Bodrum katta görülen yer darlığı ve iş akışı problemlerinden dolayı finish ve paket bölümünün zemin kata taşınması önerilmiştir. Finish ve paket bölümünün zemin kata taşınması ile zaman kayıplarının ve karışıklıkların giderilmesi öngörülmektedir. Mevcut durumda zemin katta sadece dikimhane yer almaktadır. Dolayısıyla mevcut durumda yeterince etkin kullanılmayan zemin katın da daha iyi değerlendirilmesi düşünülmüştür. Genel olarak gelecek durum için önerilen akış ile aşağıdaki iyileştirmelerin gerçekleştirilmesi planlanmıştır:

- Montaj bölümünde yer alan ve etkin kullanılamayan insan kaynakları ve cihazlar ön, arka ve yan işlem bölümlerinde kullanılmak üzere bu bölümlerde tespit edilen darboğaz noktalara yerleştirilmiştir.

- Ön, arka ve montaj bölümlerinde bulunan ve düşük verimle çalışan joker bantlar ön ve arka bölümlere ana bant olarak yerleştirilmiştir. Dikimhanede ön, arka ve montaj bölümleri ikişer banttan oluşmak üzere toplam altı ana bant oluşturulmuştur.

- Ön ve arka bantların her birinden gelen yarı mamuller ön arka eşleme operasyonu ile eşlenerek montaj bölümüne aktarılmıştır.

- Yan işlem bölümünde yer alan ön bıyık ve zımpara operasyonları darboğaz noktalar olarak tespit edilmiş ve montaj bölümünde yer alan iki eleman bu operasyonlara yerleştirilmiştir.
3.4. Gelecek Durumda Önerilen Akışın Etkisini Görmek için Simülasyon Yönteminden Yararlanılması

Gelecek durum için önerilen iyileştirilmiş süreç sonucunda mevcut sistemde nelerin değişeceğini ve mevcut sitemin bunlardan nasıl etkileneceğini görmek amacıyla simülasyon yönteminden yararlanılmıştır. Bu kapsamda öncelikle mevcut durum simülasyon modeli kurulmuş ve bu modelin mevcut sistemi tam olarak temsil ettiği doğrulanmıştır. Burada mevcut durum simülasyon modeli, gerçekteki mevcut durumun aynısıdır. Daha sonra mevcut simülasyon modeli üzerinde birtakım değişiklikler yapılarak gelecek durum simülasyon modeli kurulmuştur. Gelecek durum simülasyon modeli ile mevcut durum simülasyon modelinin çıktılarının karşılaştııımasıyla da gelecek durum için önerilen sürecin ne denli etkin/etkili olduğu görülmüştür.

3.4.1. İşletmedeki Ürün Akışına İlişsin Mevcut Durum Simülasyon Modeli

Uygulamanın kapsamını oluşturan dikimhane, yan işlem, yıkama ve finish bölümlerindeki mevcut üretim akışı simülasyon ile modellenmiştir. Simülasyon modellerinin kurulmasında ARENA 10.0 paket programından yararlanılmıştır. Tablo 1'de operasyon sürelerine ilişkin istatistiksel dağılımlar verilmiştir. Yıkama, sıkma ve kurutma makineler tarafından ger- 
çekleştirilen sabit süreli operasyonlardır. Diğer süreler için ise üçgen dağılım alınmıştır. Bu süreler belirlenirken zaman etütlerinden faydalanılmıştır. Bu kapsamda her biri farklı zamanlarda olmak üzere en az 10 gözlem değeri alınmış ve bunlara ilişkin minimum, maksimum ve ortalama süreler belirlenmiştir. Literatürde de rassal değişkenlerin minimum, maksimum ve ortalama değerlerine ilişkin çıkarımların yapılabildiği durumlarda üçgen dağılımın kullanılabileceği ifade edilmektedir (Khouja vd., 1998, 183).

Tablo 1: Operasyon Sürelerine İlişkin İstatistiksel Dağılımlar

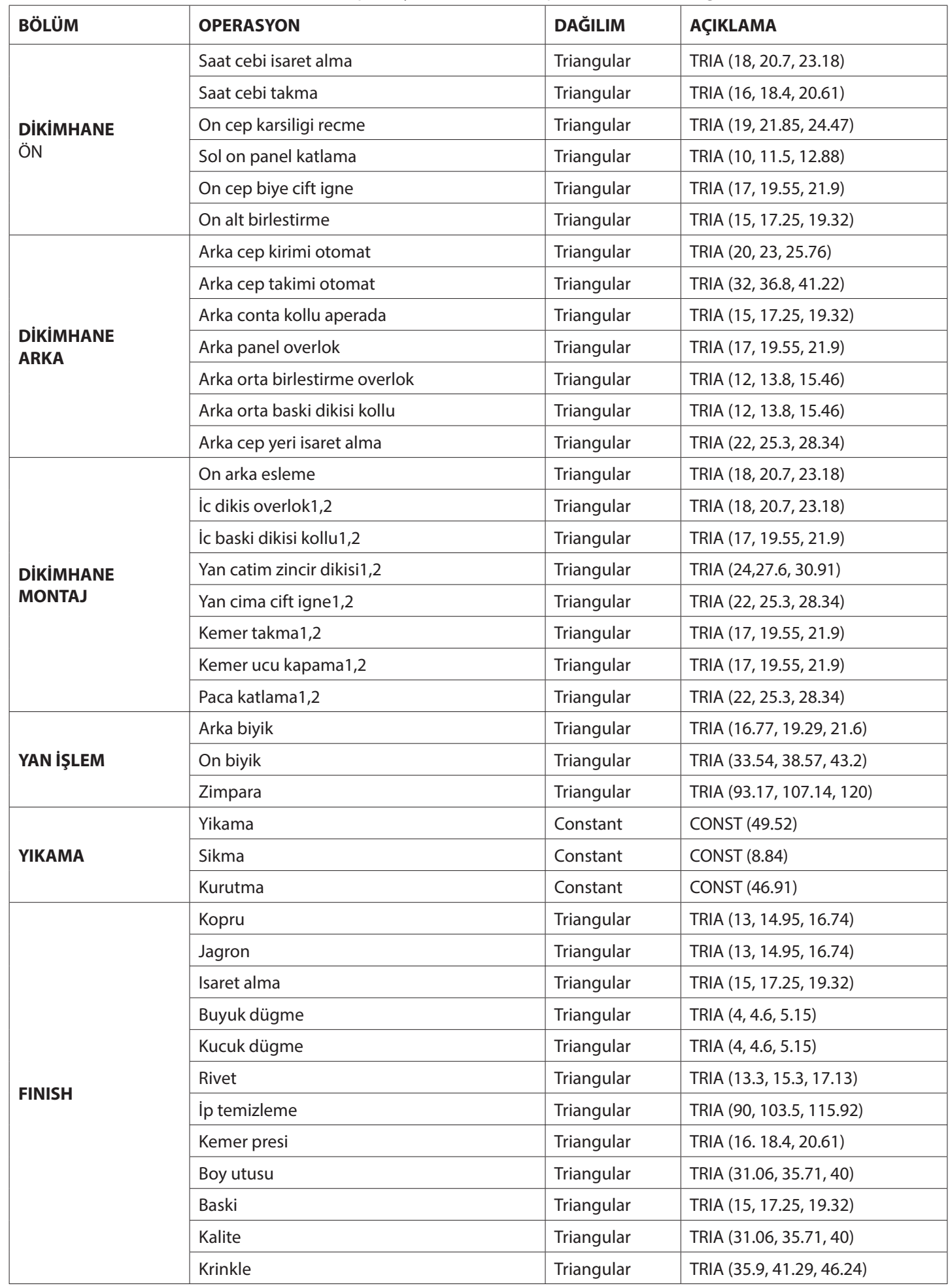


Tablo 2'de bölümlerde yer alan insan kaynakları ve cihazların dağılımı verilmiştir.

Tablo 2: Mevcut Kaynaklar

\begin{tabular}{|l|l|l|}
\hline BÖLÜM & INSAN KAYNAKLARI & CiHAZLAR \\
\hline Dikimhane- Ön & 10 & 9 \\
\hline Dikimhane- Arka & 11 & 9 \\
\hline Dikimhane- Montaj & 23 & 19 \\
\hline Yan İşlem & 3 & 1 \\
\hline Yıkama & 3 & 3 \\
\hline Finish & 12 & 9 \\
\hline
\end{tabular}

3.4.1.1. Mevcut Durum Simülasyon Modelinin Doğrulanması ve Geçerliliğinin Test Edilmesi

Simülasyon modelinin gerçek sistemi aynı şekilde yansıttığını göstermek amacıyla doğrulama (verification) yapılır. Modelde yer alan entitylerin, create modülüyle sisteme ilk girişinden dispose modülüyle sistemden çıkıncaya kadar olan bütün akışları, interactive debugger kullanılarak adım adım izlenmiş ve entitylerin sistemdeki gerekli bütün adımlardan sırasıyla geçtikleri gözlenmiştir. Buradan, sistemin doğrulandığı sonucuna varılmıştır. Yani model gerçek sistemi yeterince temsil etmektedir.

Simülasyon modelinden elde edilen çıktıların gerçek sisteme ait çıktılar ile karşılaştırılmasının yapıldığı bir aşama ise geçerlilik (validation) aşamasıdır. Bu aşamada, simülasyondan elde edilen çıktılar ile gerçek sisteme ait çıktılar t- testi yapılarak karşılaştırılmaktadır. İki ana kitle arasında, istatistiksel olarak anlamlı bir fark olmadığı tespit edilirse, modelin geçerli olduğu sonucuna varılmaktadır.

Modelin geçerlilik testi aşamasında "Nihai Ürün Sayısı" performans ölçütü olarak alınmıştır. Model ça-
Iıştırılırken tekrar uzunluğu 21 gün, tekrar sayısı 12, ısınma süresi ise 0.5 saat olarak belirlenmiştir. Tekrar uzunluğu değeri bir aydaki çalışılan gün sayısına karşılık gelmektedir. Çalışmada performans ölçütü olarak "Nihai Ürün Sayısı" alınmış ve bu ölçütün de ay bazında yıllık değeri elde edilmek istenmiştir.Tekrar sayısı bir yılda yer alan ay sayısıdır. Isınma süresi ise sistemin ilk olarak ne zaman düzenli çıktı vermeye başladığı ile ilgili bir kavramdır. Çalışmada bu süre 0.5 saattir. 2012 Eylül ile 2013 Ağustos arasındaki 12 aylık döneme ait gerçek sisteme ait geçmiş veriler elde edilmiş, bunlar simülasyon modelinden elde edilen sonuçlar ile karşılaştırılmıştır (Tablo 3).

Modelin geçerliliğinin onaylanması için t-testi kullanılmaktadır. t-testinin kullanılabilmesi için de verilerin normal dağılım göstermesi gerekmektedir. Bu noktada verilerin normal dağılım gösterip göstermediğine bakmak için Ki-kare uygunluk testi yapılmıştır.

$\mathrm{H}_{0}$ : Veriler normal dağılıma uygunluk göstermektedir.

$\mathrm{H}_{1}$ : Veriler normal dağılıma uygunluk göstermemektedir.

Tablo 3: Mevcut Durum Simülasyon Modelinden Elde Edilen Veri İle Sisteme Ait Gerçek Verinin Karşılaştırılması

\begin{tabular}{|l|c|c|}
\hline Dönem & $\begin{array}{c}\text { Simülasyon Modelinden Elde Edilen Veri } \\
\text { (Nihai Ürün Sayısı) }\end{array}$ & $\begin{array}{c}\text { Sisteme Ait Gerçek/ Geçmiş Veri } \\
\text { (Nihai Ürün Sayısı) }\end{array}$ \\
\hline 2012/ Eylül & 17550 & 17575 \\
\hline 2012/ Ekim & 17940 & 18058 \\
\hline 2012 / Kasım & 16920 & 17157 \\
\hline 2012/ Aralık & 18075 & 17950 \\
\hline 2013/ Ocak & 17295 & 17310 \\
\hline 2013/ Şubat & 17595 & 17655 \\
\hline 2013/ Mart & 18240 & 18200 \\
\hline 2013 / Nisan & 17475 & 17750 \\
\hline 2013/ Mayıs & 17475 & 17300 \\
\hline 2013 / Haziran & 17820 & 17810 \\
\hline 2013/ Temmuz & 17790 & 18000 \\
\hline 2013/ Ağustos & 18465 & 18395 \\
\hline
\end{tabular}


Ki-kare test istatistiği $X^{2}=14.13$ olarak hesaplanmıştır. Burada serbestlik derecesi $\mathrm{v}=\mathrm{k}-1-\mathrm{m}$ şeklindedir (normal dağılımda tahmin edilen parametre sayısı 2 olduğundan $m=2$ ve $k=12$ 'dir). Buradan $v=12-1-2=9$ olur. 9 serbestlik derecesi ve $\alpha=0.05$ anlamlılık düzeyi için $X^{2}$ tablo değeri $X_{a^{\prime} v=}^{2} 16.92$ şeklindedir. Sonuçta hesaplanan $X^{2}$ değeri (14.13), $X^{2}$ tablo değerinden (16.92) küçük olduğu için $H_{o}$ hipotezi kabul edilir. Yani veriler normal dağılım göstermektedir.

Artık modelin geçerliliğinin onaylanması için t-testi yapmak mümkündür. t-testi ile sisteme ait gerçek veriler ile simülasyonda elde edilen sonuçlar arasında istatistiksel olarak anlamlı bir fark olup olmadığı araştırılacaktır.

$H_{0}: \mu_{x}-\mu_{y}=0$

$\mathrm{H}_{1}: \mu_{\mathrm{x}}-\mu_{\mathrm{y}} \neq 0$

Hipotezler iki ana kitle ortalaması farkı için kurulmuş ve eşleştirilmiş örnekler için $a=0.05$ anlamlılık düzeyi için t-testi yapılmıştır. Hipotez çift yönlü olup, serbestlik derecesi de $v=12-1=11$ 'dir. Tablo değeri $\mathrm{t}_{\mathrm{v}, \mathrm{a} / 2}=\mathrm{t}_{11,0.025}=2.201$ olarak bulunur. Hesaplanan $\mathrm{t}$ değeri ise $t_{v}=t_{11}=1.051$ 'dir. Hesaplanan $t$ değeri, tablodan okunan $\mathrm{t}$ değerinden küçük olduğu için $\mathrm{H}_{0}$ hipotezi kabul edilir. Yani 0.05 anlam düzeyinde iki ana kitle ortalaması arasında istatistiksel olarak fark yoktur. Sonuçta yapılan t-testi modelin geçerli olduğunu göstermiştir.

\subsubsection{Gelecek Durum Simülasyon Modeli}

Mevcut durumda yapılması planlanan değişiklikler sonrasında sürecin iyileştirildiği durum bu model ile gösterilmiştir. Gelecek durum modeli ile birtakım iyileştirmeler elde edilmiştir. Bodrum katta görülen yer darlığı ve iş akışı problemlerinden dolayı finish bölümü zemin kata taşınmış, bu sayede zaman kayıpları ile karışıklıklar giderilmiş ve yeterince verimli kullanılmayan zemin katın değerlendirilmesi mümkün olmuştur.
Gelecek durum simülasyon modeli ile yapılan diğer düzenlemeler ise aşağıda sıralanmıştır:

- Montaj bölümünde yer alan ve etkin kullanılamayan insan kaynakları ve cihazlar ön, arka ve yan işlem bölümlerinde kullanılmak üzere bu bölümlerde tespit edilen darboğaz noktalara yerleştirilmiştir.

- Ön ve arka bantların her birinden gelen yarı mamuller ön arka eşleme operasyonu ile eşlenerek montaj bölümüne aktarılmıştır.

- Ön, arka ve montaj bölümlerinde bulunan ve düşük verimle çalışan joker bantlar ön ve arka bölümlere ana bant olarak yerleştirilmiştir.

- Dikimhanede ön, arka ve montaj bölümleri ikişer banttan oluşmak üzere toplam altı ana bant oluşturulmuştur.

- Yan işlem bölümünde yer alan ön bıyık ve zımpara operasyonları darboğaz noktalar olarak tespit edilmiş ve montaj bölümünde yer alan iki eleman bu operasyonlara yerleştirilmiştir.

Gelecek durumda önerilen model ile üretim süreçlerinde iyileştirmeler yapılmış; sonuç olarak iş yükü dengelemesi sağlanmış ve darboğaz problemi de minimize edilmiştir.

\subsection{Simülasyon Sonuçlarının Analizi ve Genel} Bir Değerlendirme

Gelecek durum simülasyon modelinde; ek bir kaynak eklemeden, yine mevcut kaynaklar ve mevcut süreler ile çalışarak aynı kalitede ancak daha fazla miktarda üretim sağlanmıştır. Performans ölçütü olarak alınan "Nihai Ürün Sayısı" nın mevcut durum simülasyon modelinden ve gelecek durum simülasyon modelinden elde edilen verilere göre karşılaştırılması Tablo 4'te gösterilmiştir. Bir yıl için yapılmış olan bu karşılaştırmada mevcut durum simülasyon modeli verilerine göre, bir yıllık nihai ürün sayısının 212640 ve nihai ürün sayısının aylık ortalamasının ise 17720 olduğu görülmüştür. 
Tablo 4: Mevcut Durum Simülasyon Modelinden Elde Edilen Veri Ille Gelecek Durum Simülasyon Modelinden Elde Edilen Verinin Karşılaştırılması

\begin{tabular}{|c|c|c|}
\hline Dönem & $\begin{array}{c}\text { Simülasyon Modelinden Elde Edilen Veri } \\
\text { (Nihai Ürün Sayısı) }\end{array}$ & $\begin{array}{l}\text { Gelecek Durum Simülasyon Modelinden Elde Edilen Ver } \\
\text { (Nihai Ürün Sayısı) }\end{array}$ \\
\hline 2012/ Eylül & 17550 & 30301 \\
\hline 2012/ Ekim & 17940 & 19622 \\
\hline 2012/ Kasım & 16920 & 27991 \\
\hline 2012/ Aralık & 18075 & 28906 \\
\hline 2013/Ocak & 17295 & 29086 \\
\hline 2013/Şubat & 17595 & 27737 \\
\hline 2013/Mart & 18240 & 29161 \\
\hline 2013/ Nisan & 17475 & 25562 \\
\hline 2013/ Mayıs & 17475 & 18767 \\
\hline 2013/ Haziran & 17820 & 25038 \\
\hline 2013/Temmuz & 17790 & 28501 \\
\hline 2013/ Ağustos & 18465 & 22337 \\
\hline Toplam & 212640 & 313009 \\
\hline Ortalama & 17720 & 26084 \\
\hline
\end{tabular}

Diğer yandan, gelecek durum simülasyon modeli verilerine göre ise, bir yıllık Nihai Ürün Sayısının 313009 ve Nihai Ürün Sayısının aylık ortalamasının 26084 olduğu görülmüştür. Mevcut durum ile gelecek durum karşılaştıııldığında; gelecek durum simülasyon modelinden elde edilen yıllık "Nihai Ürün Sayısı" mevcut durum simülasyon modelinden elde edilen yıllık "Nihai Ürün Sayısı"ndan 100369 adet daha fazladır. Bu bulgulardan yola çıkarak, mevcut durum simülasyon modeli verilerine oranla, gelecek durum simülasyon modelinin nihai ürün sayısında \% 47 oranında artış olduğu görülmüştür. Bu üretim artışının firmaya sağladığı yıllık kazanç ise ortalama 602214 TL değerindedir.

\section{SONUÇ}

Türkiye'de tekstil sektörü yarattığı istihdam ve yüksek ihracat potansiyeli ile ülke ekonomisinin lokomotif sektörlerinden birisi konumundadır. Buna rağmen, plansız büyüme ve yatırımlar, maliyet artışları, pazar darlığı, markalaşamama ve imaj sorunu, üretim akışındaki aksaklıklar ve kalite problemleri tekstil sektöründe faaliyet gösteren işletmeleri tehdit etmektedir.

Bu çalışmanın amacı bir imalat işletmesinde süreç iyileştirme çalışmasının yapılması ve bunun sonucunda işletmenin elde edeceği kazanımların belirlenerek bir yol haritasının gösterilmesidir. Bu kapsamda, tekstil sektöründe faaliyet gösteren bir işletme ele alınmış ve bu işletmenin ürettiği ürünlerden bir tanesinin akışı ele alınarak, söz konusu işletmenin üretimindeki aksaklıklar tespit edilmiş ve bunların ortadan kaldırılmasına çalışılmıştır.

Çalışmaya konu olan imalat işletmesinde mevcut durumda hat içinde yer alan insan kaynakları ve cihaz- lar etkin kullanılamamaktadır. Etkin kullanılamayan kaynaklar verimsiz işgücüne neden olmakta, bu durum da nihai ürün sayısını düşürmektedir. Darboğaz noktalar tespit edilip, problemlere çözüm üretilemediğinden dolayı hat dengeleme problemleriyle karşılaşılmaktadır.

Mevcut durumdaki yerleşim planı da etkinliği düşüren bir diğer faktör olarak karşımıza çıkmaktadır. Mevcut durumda kullanılan bodrum ve zemin katlar gelecek durumda da kullanılmış ancak bölümlerin yerleşimi önceki duruma kıyasla iş akışını daha kolay hale getirecek şekilde planlanmıştır. Gelecek durumda önerilen yerleşim planı sayesinde mevcut durumdaki yerleşimden kaynaklanan atıl kaynakların olması, iş akışında karışıklıkların yaşanması, zaman kayıplarının olması, sevkiyatın zamanında yapılamaması, termin sürelerine uyulamaması, fazla mesailer, ek maliyetler, çalışanların performanslarında yaşanan düşüşler gibi problemler ortadan kaldırılmıştır.

Gelecek durum simülasyon modelinde, ek bir kaynak eklemeden mevcut durumdaki aynı kaynaklarla ve aynı sürede çalışılarak aynı kalitede daha fazla üretim sağlanmıştır. Ayrıca üretimde yaşanan zamanlama problemi giderilmiş bu sayede terminlere uyum sağlanmıştır. Mevcut durum ile gelecek durum karşılaştırıldığında mevcut durum simülasyon modelinin ve gelecek durum simülasyon modelinin Nihai Ürün Sayısı arasında yıllık 100369 adet fark olduğu ve bunun da aylık ortalama olarak 8364 adete, yani mevcut duruma göre yıllık \% 47 oranında bir artışa karşııık geldiği tespit edilmiştir.

Bu çalışmanın uygulaması, bir tekstil işletmesinin 
ürettiği ürünlerden/modellerden birisine odaklanılarak gerçekleştirilmiştir. Bu yüzden, çalışmadan elde edilen sonuçlar önemli olsa da, tekstil sektörü genelinde yorum yaparken dikkatli olunmalıdır. Bu çalışmadan farklı olarak, gelecekte süreç iyileştirilmesini konu alan; farklı sektörlerden işletmelerde uygulamaların gerçekleştirilmesi düşünülebilir.

\section{SON NOTLAR}

"Bu çalışma Yrd. Doç. Dr. Nuri Özgür DOĞAN'ın danışmanlığında Ebru TAKCI tarafından Nevşehir Hacı Bektaş Veli Üniversitesi Sosyal Bilimler Enstitüsü İşletme Anabilim Dalında tamamlanan "Bir İmalat İşletmesinde Simülasyon Yardımıyla Süreç İyileştirme Uygulaması: Kayseri Gürkar Tekstil Örneği” başlıklı yüksek lisans tezinden türetilmiştir.

\section{KAYNAKLAR}

Alkaya, E. and Demirer, G.N. (2014) "Sustainable Textile Production: A Case Study from a Woven Fabric Manufacturing Mill in Turkey" Journal of Cleaner Production, 65: 595-603.

Baddoo, N. and Hall, T. (2003) "De- motivators for Software Process Improvement: An Analysis of Practitioners' Views" Journal of Systems and Software, 66(1): 23-33.

Beecham, S., Hall, T. and Rainer, A. (2005) "Defining a Requirements Process Improvement Model" Software Quality Journal, 13: 247-279.

Bozkurt, R. (2003) "Süreç İyileştirme” 3. Basım, Ankara, MPM.

Brahmadeep and Thomassey, S. (2014) "A Simulation Based Comparison: Manual and Automatic Distribution Setup in a Textile Yarn Rewinding Unit of a Yarn Dyeing Factory" Simulation Modelling Practice and Theory, 45: 80-90.

Chan, K., K. and Spedding T., A. (2003) "An Integrated Multidimensional Process Improvement Methodology for Manufacturing Systems" Computers \& Industrial Engineering, 44(4): 673-693.

Chen, J.C., Chen, C.-C., Su, L.-H, Wu, H.-B. and Sun, C.-J. (2012) "Assembly Line Balancing in Garment Industry" Expert Systems with Applications, 39: 1007310081.

Eleren, A., (2007). "Eğitim Başarısının Artırılmasında Süreç Geliştirme Yöntemlerinin Kullanılması ve Bir Uygulama”. Afyon Kocatepe Üniversitesi İIBF Dergisi, 9(2): $1-25$.

Eroğlu, C. (2006) "Süreç İyileştirme ve Bir Uygulama” Yüksek Lisans Tezi, İstanbul, Marmara Üniversitesi Sosyal Bilimler Enstitüsü.

Forsyth, H.L. and Porter, K. (2000) "Production Planning and Control Improvements in a Small UK Garment Manufacturer: A Case Study". Production Planning \& Control: The Management of Operations, 11(6): 617-625.

Freire, J. and Alarcon, L. (2002) "Achieving Lean De- sign Process: Improvement Methodology" Journal of Construction Engineering and Management, 128(3): 248-256.

Greasley, A. (2008) "Using Simulation for Facility Design: A Case Study" Simulation Modelling Practice and Theory, 16: 670-677.

Hashemipour, M. (2004) "Integration of Process Planning and Scheduling for Outsourcing in the Apparel Industry" The Journal of The Textile Institute, 95(1-6): 9-18.

Holmes, D., Aluise, T., Burt, K. and Ellsworth, S. (1998) "Combining SPC with APC to Improve Quality" Quality Engineering, 10(3): 575-578.

Islam, M., Khan, A.M. and Khan, M.R. (2013) "Minimization of Reworks in Quality and Productivity Improvement in the Apparel Industry" International Journal of Engineering and Applied Sciences, 1(4): 147-164.

İnce, A.R., Erol, Y. ve Karagöz, N. (2013) "Bir Süreç İyileştirme Örneği Olarak Görüntü Arşivleme ve İletişim Sisteminin (Pacs) Değerlendirilmesi (Sivas Numune Hastanesi Uygulaması)" İ̧sletme Araşttrmaları Dergisi, 5(3): 243-257.

Kamath, B.G., Pai, R., Hebbar, S. and Rao, V. (2013) "Process Improvement In Manufacturing Industries: A System Dynamics Perspective" Proceedings of IRAJ International Conference, 10th August 2013, Pune, India.

Kaya, İ ve Ağa, A. (2004) "Kalite İyileştirme Sürecinin Yedi Temel Aracı ve Motor-Traktör İmalatı Yapan Bir İşletmede Uygulanması" Selçuk Üniversitesi Sosyal Bilimler Enstitüsü Dergisi, 11: 447-468.

Khouja, M., Shelnutt, J.W. and Wilmot, M. (1998) "The Economics of Air Conditioning for Precision Manufacturing: A Simulation Model" Integrated Manufacturing Systems, 9(3): 182-192.

Kwong, C.K., Mok, P.Y. and Wong, W.K. (2006) "Determination of Fault-Tolerant Fabric-Cutting Schedules in a Just-In-Time Apparel Manufacturing Environment" International Journal of Production Research, 44(21): 4465-4490.

Laoboonlur, P., Hodgson, T.J. and Thoney, K.A. (2006) "Production Scheduling in a Knitted Fabric Dyeing and Finishing Process" The Journal of The Textile Institute, 97(5): 391-399.

Monks, J., G. (1996) "İşlemler Yönetimi” S. Üreten (2.Bas. Çev.), İstanbul,Nobel Yayıncılık.

Mukhopadhyay, A.R. and Ray, S. (2006) "Reduction of Yarn Packing Defects Using Six Sigma Methods: A Case Study" Quality Engineering, 18(2): 189-206.

Niazi, M., Wilson, D. and Zowghi, D. (2005) "A Maturity Model for the Implementation of Software Process Improvement: an Empirical Study" The Journal of Systems and Software, 74(2): 155-172.

Pino, F. J., Garcia, F. and Piattini M. (2008) "Software Process Improvement in Small and Medium Software Enterprises a Systematic Review" Software Quality Journal, 16: 237-261. 
Raja, R. and Suryaprakasa Rao, K. (2007) "Performance Evaluation Through Simulation Modeling in a Cotton Spinning System" Simulation Modelling Practice and Theory, 15: 1163-1172.

Sarıaslan, H. (1986) "Sira Bekleme Sistemlerinde Simülasyon Tekniği” 1. Basım, Ankara, Ankara Üniversitesi Siyasal Bilgiler Fakültesi Yayınları.

Schiefer, G. (2002) "Environmental Control for Process Improvement and Process Efficiency in Supply Chain Management- the Case of the Meat Chain" International Journal of Production Economics, 78(2): 197-206.

Şener, T. ve Kılınç, N. (2013) "Hazır Giyim İşletmelerinde Karşılaştırma Yolu ile Üretim Süreçlerinin İyileştirilmesi" Selçuk Üniversitesi, İktisadi ve İdari Bilimler Fakültesi Sosyal ve Ekonomik Araştırmalar Dergisi, 13(25): 445-464.

Tang, Z.-X., Wang, X., Fraser, W.B. and Wang, L. (2006) "Simulation and Experimental Validation of a Ring Spinning Process" Simulation Modelling Practice and Theory, 14: 809-816.

T.C. Bilim, Sanayi ve Teknoloji Bakanlığı, (2013). "Tekstil, Hazırgiyim ve Deri Ürünleri Sektörleri Raporu (2013/2)”.

T.C. Ekonomi Bakanlığı, (2014). "Ekonomik Görünüm, Eylül 2014”.

Tezsürücü, D. ve Tunail, İ. (2010) “Altı Sigma Metodolojisi ve Otomotiv Sektöründe Bir Örnek Olay İncele- mesi” Celal Bayar Üniversitesi SBE, Sosyal Bilimler Dergisi, 8(1):129-146.

Tütüncü, Ö., Doğan, Ö.İ. ve Topoyan, M. (2004) "Süreçlerle Yönetim ve Bir Hizmet İşletmesi Uygulaması" IV. Ulusal Üretim Araştırmaları Sempozyumu, Selçuk Üniversitesi, Konya, s. 354-260.

Webb, C.J., Waters, G.T., Liu, G.P. and Thomas, E.J.C. (2010) "The Use of Visualisation and Simulation Techniques to Model the Splicing Process" The Journal of The Textile Institute, 101(10): 859-869.

Wong, W.K. and Chan, C.K. (2001) "An Artificial Intelligence Method for Planning the Clothing Manufacturing Process" The Journal of The Textile Institute, 92(2): 168-178.

Yang, C.-L., Huang, R.-H. and Huang, H.-L. (2011) "Elucidating a Layout Problem in the Fashion Industry by Using an Ant Optimisation Approach" Production Planning \& Control: The Management of Operations, 22(3): 248-256.

Yılmazer, A ve Sarıaltın, H. (2011) “KOBİlerde Süreç Yönetimi Uygulamalarının İncelenmesi: Sakarya İli I. Organize Sanayi Bölgesi Örneği” Uludă̆ Üniversitesi İktisadi ve Idari Bilimler Fakültesi Dergisi, 30(2): 155-186.

Zülch, G., Koruca, H.I. and Börkircher, M. (2011) "Simulation-Supported Change Process for Product Customization- A Case Study in a Garment Company" Computers in Industry, 62: 568-577. 
